\title{
ENSINO SUPERIOR NA PERSPECTIVA DA PESSOA COM DEFICIÊNCIA, CONDIÇÕES DE ACESSO, PERMANÊNCIA E SUCESSO
}

\author{
Dafne Sousa de Oliveira ${ }^{\mathrm{i}}$ \\ Maria Edith Romano Siems-Marcondes ${ }^{\text {ii }}$
}

\section{Resumo}

Este artigo analisa a vivência de estudantes com deficiência em relação às condições de acesso, permanência e sucesso no percurso do ensino superior. Fundamenta-se nos pressupostos da pesquisa qualitativa e adota como fundamento teórico-metodológico a perspectiva da História Oral. O procedimento metodológico utilizado neste trabalho foi a realização de entrevistas temáticas com estudantes com deficiência matriculados no ensino superior e com representante do Núcleo de Acessibilidade de uma universidade federal. Os resultados são analisados nas seguintes categorias: o acesso de pessoas com deficiência ao ensino superior na perspectiva dos estudantes; condições de acessibilidade e seus impactos na permanência; tecnologias assistivas e de relações sociais. Concluímos que na perspectiva dos estudantes os processos seletivos que dão acesso ao Ensino superior têm homogeneizado as deficiências o que dificulta a inserção dos estudantes na universidade. Além disso, apesar dos avanços nas políticas de inclusão e na postura da comunidade acadêmica, ainda temos ajustes a fazer, para que haja real acessibilidade no ensino superior.

Palavras-chave: História Oral. Ensino superior. Deficiência

\section{ENSEÑANZA SUPERIOR EN LA PERSPECTIVA DE LA PERSONA CON DISCAPACIDAD, CONDICIONES DE ACCESO, PERMANENCIA Y ÉXITO}

\begin{abstract}
Resumen
Este artículo analiza la vivencia de estudiantes con discapacidad en relación a las condiciones de acceso, permanencia y éxito en el curso de la enseñanza superior. Se fundamenta en los presupuestos de la investigación cualitativa y adopta como fundamento teórico-metodológico la perspectiva de la Historia Oral. El procedimiento metodológico utilizado en este trabajo fue la realización de entrevistas temáticas con estudiantes con discapacidad matriculados en la enseñanza superior y con representante del Núcleo de Accesibilidad de una universidad federal. Los resultados se analizan en las siguientes categorías: el acceso de las personas con discapacidad a la enseñanza superior desde la perspectiva de los estudiantes; condiciones de accesibilidad y sus impactos en la permanencia; tecnologías asistivas y de relaciones sociales. Concluimos que en la perspectiva de los estudiantes los procesos selectivos que dan acceso a la Enseñanza Superior han homogeneizado las deficiencias lo que dificulta la inserción de los estudiantes en la universidad. Además, a pesar de los avances en las políticas de inclusión y en la postura de la comunidad académica, todavía tenemos ajustes a hacer, para que haya real accesibilidad en la enseñanza superior.
\end{abstract}

Palabras clave: Historia Oral. Enseñanza superior. Deficiencia 


\section{Introdução}

Este trabalho tem o objetivo de conhecer a perspectiva de estudantes com deficiência que estão matriculados no curso de Psicologia da Universidade Federal de Roraima - UFRR, em relação a questões de acesso, permanência e condições para o sucesso acadêmico.

A pesquisa foi realizada no contexto do projeto "Educação e deficiência na voz de quem vive essa trama: trajetórias escolares de pessoas com deficiência:”, desenvolvido por um grupo de pesquisa vinculado à profissionais do Centro de Educação da UFRR e o recorte aqui apresentado constituiu o trabalho de conclusão de curso de uma estudante do curso de Licenciatura em Pedagogia.

Entendemos, como nos dizem Marques e Marques (2003) que, quando estudantes da área pedagógica ouvem o que os acadêmicos com deficiência têm a dizer e transformam suas vozes em produção científica, oportunizam à comunidade universitária refletir sobre o desafio de cumprir um de seus papéis sociais que é o de explicitar as contradições sociais e propor alternativas concretas para sua superação.

O projeto parte da premissa de que é relevante identificar aspectos da vida escolar de pessoas com deficiência que impactaram em seu percurso acadêmico no sentido de que se compreenda melhor o que contribuiu para o acesso, permanência e sucesso no ensino superior. O horizonte é, a partir da compreensão dessas contribuições, pensar estratégias de acesso e acessibilidade para outros estudantes com deficiência que almejem formação em nível superior.

De acordo com Siqueira e Santana (2010), os resultados de um estudo com essa temática podem fornecer subsídios para implementação do acesso dos estudantes com necessidades educacionais especiais à educação superior, permitindo assim que a universidade cumpra seu papel de agente de transformação social e institucional. Pode ainda fomentar o debate sobre a qualidade do acesso ao conhecimento nos cursos universitários, favorecendo que ajustes ou modificações nos aspectos espaciais, metodológicos, de materiais didáticos ou tecnologia assistiva e de comunicação sejam feitos, diversificando as opções educativas para que os estudantes desenvolvam com êxito o currículo proposto.

Nesse estudo ouvimos estudantes universitários com deficiência e analisamos sua percepção sobre as dificuldades/facilidades, relação com os professores e com os colegas de curso e principalmente as condições de acessibilidade ao conhecimento dos fundamentos da profissão que pretendem exercer. Nesse sentido, identificamos o papel relevante das políticas públicas federais ocorridas a partir dos anos 2000 para inclusão de pessoas com deficiência no ensino superior e seu impacto nas relações estabelecidas no âmbito acadêmico. 


\section{Metodologia}

O fundamento teórico-metodológico adotado nesta pesquisa é de abordagem qualitativa, considerando que visamos interpretar opiniões, ressignificar ideias e atribuir significados ao conjunto dos dados, que foram construídos na perspectiva da história oral. No entendimento de Cajueiro (2013, p. 23):

A pesquisa qualitativa difere basicamente da pesquisa quantitativa pelo fato de não utilizar dados estatísticos. Nela se prioriza as percepções de atitude e aspectos subjetivos dos objetos de pesquisa interagindo em seu grupo. É descritiva. As informações obtidas não são quantificadas. A interpretação de fenômenos e a atribuição de significados são básicas no processo de pesquisa qualitativa.

Nosso objetivo é conhecer e compreender trajetórias de vida escolar de estudantes de ensino superior com deficiência, tomando como entrevistadas pessoas que podem, no relato oral de suas vivências e dos fatos que envolvem seu ponto de vista acerca do tema da pesquisa, recuperar informações preciosas ao entendimento do contexto.

Como salienta Bosi (2003), as entrevistas provocam memórias, trazem lembranças, estimulam reflexões autobiográficas que podem fragilizar emocionalmente os participantes da pesquisa, e em decorrência disto, a sensibilidade e o respeito devem pautar o trabalho do pesquisador.

Refletindo sobre a pertinência do uso dessa metodologia, Alberti (2004, pp. 30 - 31):

É preciso compreender que a opção pela história oral depende intrinsecamente do tipo de questão colocada ao objeto de estudo. Por outro lado, ela também depende de haver condições de se desenvolver a pesquisa: não é apenas necessário que estejam vivos aqueles que podem falar sobre o tema, mas que estejam disponíveis e em condições (físicas e mentais) de empreender a tarefa que lhes será solicitada.

Nosso foco de interesse reunia todas essas condições e, no processo de entrevistas, foram adotados todos os cuidados que evitassem causar incômodo ou rejeição no tratamento do tema preservando o equilíbrio dos sujeitos atendendo, inclusive, compromissos éticos da pesquisa com seres humanos. Além disso, no tratamento dos documentos orais seguimos o que nos recomenda Alberti (2005, p . 08):

No caso da entrevista de história oral, a intencionalidade do documento já é dada de saída, quando da própria escolha do entrevistado como pessoa importante a ser ouvida a respeito do assunto estudado. E ela se prolonga por todas as etapas de realização e tratamento da entrevista, transformada em documento de um acervo, aberta à consulta de pesquisadores.

O projeto foi analisado e considerado conforme pelo Comitê de Ética em Pesquisa com seres humanos da Universidade Federal de São Carlos e obtivemos o parecer de número 528/2009, para a realização das entrevistas. No recorte que apresentamos nesse artigo, foram tomadas como referências as entrevistas de três estudantes cujos perfis serão descritos mais adiante e que foram entrevistados em espaços da própria universidade onde estudam, em espaço reservado e com estrita observação das reações do entrevistado diante das questões que lhe eram apresentadas e sem insistência em temas com os quais se observasse qualquer desconforto. 
Consideramos de grande importância que o entrevistado soubesse da validade de sua contribuição para a pesquisa, e o quanto conhecer sua história de vida acrescentaria para o resultado do trabalho. Do nosso ponto de vista, compreender como viveram, e como elucidaram questões que atrapalhavam o seu sucesso nos ajudou, como pesquisadores da área, a contribuir com a produção científica na área.

\section{Deficiência e educação}

O conceito de deficiência que nos embasa é o modelo social de deficiência, que entende que a condição de deficiência é decorrente das consequências da articulação entre as condições biológicas de cada pessoa e as condições do plano social que impedem que a pessoa viva uma vida social plena.

É importante destacar que a sociedade pode apresentar muitas barreiras que assumem um protagonismo cotidiano, o que acaba por fazer com que alguns indivíduos sejam alijados da participação social e dando a entender que a incapacidade está instalada no sujeito e não na sociedade em que ele vive. Entendemos que tais barreiras podem ser rompidas com ajustes comportamentais e estruturais por vezes relativamente simples.

O decreto federal n. 6949/2009, instrumento legal que em âmbito brasileiro, promulga a Convenção Internacional sobre os Direitos das Pessoas com Deficiência e seu protocolo facultativo, também traz esta perspectiva de ênfase do social para a concepção de deficiência ao definir que:

Pessoas com deficiência são aquelas que têm impedimentos de longo prazo de natureza física, mental, intelectual ou sensorial, os quais, em interação com diversas barreiras, podem obstruir sua participação plena e efetiva na sociedade em igualdades de condições com as demais pessoas (BRASIL, 2009).

Acompanhando essas ideias, Diniz (2003, p. 1) enfatiza também os aspectos sociais não consideram apenas a questão fisiológica, mas a leitura que a sociedade faz dessa diferença, como se representasse incapacidade:

Deve-se entender deficiência como um conceito amplo e relacional. É deficiência toda e qualquer forma de desvantagem resultante da relação do corpo com lesões e a sociedade. Lesão, por sua vez, engloba doenças crônicas, desvios ou traumas que, na relação com o meio ambiente, implica em restrições de habilidades consideradas comuns às pessoas com mesma idade e sexo em cada sociedade. Lembro que deficiência é um conceito aplicado a situações de saúde e doença e, em alguma medida, é relativo às sociedades onde as pessoas deficientes vivem.

Nesse sentido, a deficiência é entendida como uma condição de desvantagem que é definida na relação com o outro, encaixado em sentidos subjetivos de normalidade da sociedade em que vive. Assim, Silva (2006, p. 117) afirma que: 
A sociedade marcada pela diversidade/multiplicidade das diferenças humanas [...] incorpora também os indivíduos que não se encaixam nos chamados padrões de normalidade física ou mental, devido as causas acidentais ou congênitas que os tornaram pessoas com deficiências e enfrentam barreiras sociais diferenciadas, já que, em grande medida, o meio determina o efeito de uma deficiência ou de uma capacidade sobre a vida cotidiana de uma pessoa. Ela pode se perceber relegada à invalidez se lhe são negadas oportunidades necessárias aos aspectos fundamentais da vida, tais como trabalho, educação, habitação e lazer .

Sendo assim, a eliminação das barreiras sociais pode favorecer a autonomia e independência das pessoas com deficiência neutralizando ou minimizando impactos decorrentes de sua disfunção orgânica e potencializando sua capacidade de viver em sociedade. Aprofundando essa discussão:

O modelo social da deficiência baseia-se na proposição de que a sociedade e as suas instituições é que são opressivas, discriminadoras e incapacitantes e que a atenção, portanto, precisa estar direcionada para a remoção dos obstáculos existentes à participação das pessoas portadoras de deficiências na vida em sociedade e para a mudança institucional, ou seja, para a mudança de regulamentos e de atitudes que criam e mantêm e exclusão (MITTLER, 2003, p. 26)

Um conceito decorrente do modelo social de deficiência, é o de acessibilidade, como condição para a utilização, com segurança e autonomia, total ou assistida, dos espaços, mobiliários e equipamentos urbanos, das edificações, dos serviços de transporte e dos dispositivos, sistemas e meios de comunicação e informação, por pessoa com deficiência ou com mobilidade reduzida (BRASIL, 2004). Nossa perspectiva é de que devam ser rompidas as barreiras que impedem a pessoa com deficiência de ser incluída no plano social e de ter acesso aos saberes que lhes são inalienável direito.

\subsection{Ensino superior e deficiência}

O direito à educação é garantido pela Constituição Federal de 1988 em seu Artigo 208, que estabelece garantias de que esse dever do Estado será efetivado, com a oferta do atendimento educacional especializado as pessoas com deficiência que deve ser ofertado preferencialmente na rede regular de ensino (BRASIL, 1988).

Decorrem dessa norma constitucional, documentos como a Política Nacional de Educação Especial na Perspectiva da Educação Inclusiva que tem como objetivo:

[...] assegurar a inclusão escolar de alunos com deficiência, transtornos globais do desenvolvimento e altas habilidades/superdotação, orientando os sistemas de ensino para garantir: acesso ao ensino regular, com participação, aprendizagem e continuidade nos níveis mais elevados do ensino; transversalidade da modalidade de educação especial desde a educação infantil até a Educação Superior; oferta do atendimento educacional especializado; formação de professores para o atendimento educacional especializado e demais profissionais da educação para a inclusão; participação da família e da 
comunidade; acessibilidade arquitetônica, nos transportes, nos mobiliários, nas comunicações e informação; e articulação intersetorial na implementação das políticas públicas (Brasil, 2008, p.14).

Então, o que essa Política normatiza não é apenas o acesso, mas também a garantia de que as instituições de ensino assegurem o aprendizado e a continuidade da escolarização da pessoa com deficiência, dando o suporte necessário para o aprendizado do aluno. Pieczkowski e Naujorks (2014, p. 113), destacam que:

A efetivação de aparatos legais é necessária para uma educação inclusiva no Ensino superior brasileiro, todavia, por si só não garante a concretização de políticas e programas inclusivos. Uma educação que prime pela inclusão deve ter, necessariamente, investimentos em materiais pedagógicos, em qualificação de professores, em infraestrutura adequada para ingresso, acesso e permanência, além de estar atenta a qualquer forma discriminatória.

Nesse aspecto, não basta haver políticas, é preciso que existam subsídios para a sua efetivação, pessoal qualificado e que compreenda o processo de inclusão escolar da pessoa com deficiência, além de financiamento para as questões arquitetônicas e materiais. Na definição de Ferreira (2007, p. 44)

[...] incluir significa organizar e implementar respostas educativas que facultem a apropriação do saber, do saber fazer e da capacidade crítica e reflexiva; envolve a remoção de barreiras arquitetônicas sim, mas sobretudo das barreiras atitudinais-aquelas referentes ao "olhar" das pessoas normais e desinformadas - para que se promova a adequação do espaço psicológico que será compartilhado por pessoas muito diferentes entre si.

Um desafio que, nas políticas e práticas de ensino superior, ainda depende de ampliação de saberes, considerando que a chegada dos estudantes com deficiência no ensino superior é situação relativamente recente em nossa história da educação e que ainda demanda a realização de investigações que embasem melhores práticas.

\section{Um percurso de pesquisa}

Em uma primeira etapa desta pesquisa fizemos uma aproximação com o campo de estudos, por meio de revisão da literatura, com levantamento bibliográfico em acervos eletrônicos e em livros disponibilizados na biblioteca institucional. Buscamos conhecer estudos que tinham como objeto a presença de estudantes com deficiência no ensino superior e fundamentos teóricos e metodológicos relativos à história oral, com vistas a consolidar uma base teórica para este estudo.

Adotamos a perspectiva de Alberti (2005) de que é conhecendo e estudando o material disponível em arquivos, bibliotecas e outras instituições que se garante a qualidade do trabalho seguinte. Em nosso 
caso consultamos publicações em livros e artigos coletados em periódicos científicos especializados da área da educação especial.

A segunda etapa foi a escolha dos entrevistados, feita em consulta ao banco de dados de alunos com deficiência matriculados no Centro de Educação da UFRR, que conta com os cursos de Psicologia, Pedagogia e Educação no Campo. No curso de Psicologia há três alunos com deficiência que cursam semestres distintos, já no curso de Pedagogia não há matrícula de alunos com deficiência. O curso de Licenciatura em Educação no Campo foi excluído da pesquisa, pois os alunos estudam em período de alternância escola/comunidade o que dificultaria a realização das entrevistas.

De posse dessas informações, fizemos o contato inicial com os alunos do curso de Psicologia e todos concordaram em participar. Dessa forma, realizamos a gravação das entrevistas com instrumentos de gravação (celulares e notebooks). O roteiro das entrevistas a serem aplicadas, foi o convencionado pela equipe responsável pelo macro-projeto e já havia sido enviado pela coordenação do grupo de pesquisa.

Entendemos, em relação à entrevista que, "sua função é dupla: promove a síntese das questões levantadas durante a pesquisa [...] e constitui instrumento fundamental para orientar as atividades subseqüentes, especialmente a elaboração de roteiros individuais" (ALBERTI, 2004, p. 83).

No decorrer da pesquisa, identificamos a necessidade de ouvir representantes do núcleo de acessibilidade da universidade, visto que, na escuta dos estudantes, observamos que este órgão de apoio e os que lá atuam são de extrema importância para o percurso formativo dos estudantes com deficiência. Trata-se de uma equipe multiprofissional com formação em serviço social, psicologia, e técnicos administrativos, que contam com o apoio de bolsistas selecionados entre alunos da universidade.

Foram observadas circunstâncias favoráveis à realização de uma entrevista como: local, duração, postura do entrevistador, pessoas presentes na entrevista e o equipamento de gravação. Para assegurar o anonimato dos participantes utilizaremos como codinomes os indicativos: A-1, A-2 e A-3 (alunos) e B-1 (representante do Núcleo de Acessibilidade).

A terceira etapa, foi a transcrição e correção das entrevistas, e sua aprovação pelos entrevistados em acordo com o previsto no Comitê de Ética em Pesquisa em Seres Humanos que nos autorizou à execução do trabalho através do Parecer n 528/2009 da Universidade Federal de São Carlos (universidade que sedia o macro-projeto).

A última etapa foi a análise dos dados, contextualizando com referenciais teóricos que nos auxiliaram a embasar esse trabalho. $\mathrm{Na}$ análise das entrevistas dos estudantes matriculados no curso de Psicologia, destacamos as seguintes categorias: motivações dos estudantes para a escolha do curso; as condições de acesso à UFRR confrontando o que a Universidade apresenta e qual a perspectiva dos 
estudantes; condições de acessibilidade e permanência na universidade em relação ao apoio especializado, equipamentos tecnológicos e acompanhamento pedagógico.

\subsection{Estudantes com deficiência no Centro de Educação}

Os participantes desta pesquisa são três alunos do curso de Psicologia da Universidade Federal de Roraima, cujos perfis descreveremos a seguir e um representante da coordenação do Núcleo de Acessibilidade.

O primeiro participante de nossa pesquisa, apresenta baixa visão. Não se sabe ao certo se esta decorreu do nascimento prematuro ou de uma infecção hospitalar que ocorreu na época de seu nascimento. Em termos de condições sociais e econômicas, a renda familiar é de até três salários mínimos e o aluno recebe uma bolsa junto de apoio à permanência, originada do Programa Incluir, em um valor que é inferior à metade de um salário mínimo, em contrapartida à prestação de serviços à Universidade. $\mathrm{O}$ ano de ingresso na Universidade foi 2015.

O segundo participante da pesquisa relata cegueira adquirida por acidente com explosivo durante atividade profissional aos 19 anos. É pastor em uma igreja protestante e dedica o seu tempo aos estudos e ao trabalho missionário que foi o que impulsionou a sua escolha pela área da Psicologia na UFRR. Ingressou no ano de 2013.

O terceiro entrevistado relata dificuldade de aprender e uma deficiência física congênita: a mielomeningocele, que é uma malformação da coluna vertebral da criança em que as meninges, a medula e as raízes nervosas estão expostas. Também é bolsista do Programa Incluir e ingressou na universidade no ano de 2013.

$\mathrm{Na}$ análise dos dados de entrevista já transcritas, optamos por trabalhar, neste estudo, apenas com os alunos com deficiência visual, pela semelhança das limitações funcionais e pelas regularidades observadas em suas entrevistas.

Em comum, observamos que todos são oriundos de famílias com baixa renda e que realizaram seus percursos escolares integralmente em escolas públicas. Em seus percursos tiveram acesso a alguns atendimentos especializados e contavam, para permanência no ensino superior, com o apoio familiar e de amigos.

\section{2 A Psicologia como área de formação}


O curso de Psicologia da Universidade Federal de Roraima é um curso de bacharelado criado pela Resolução n. 008/2005 - CUNI - UFRR e reconhecido pelo DOU Portaria n. 493 de 20/12/2011. No período em que realizamos nossa pesquisa, o curso contava com treze professores efetivos e dois substitutos todos com formação pelo menos em grau de mestrado. Segundo o Projeto Político Pedagógico do Curso, reformulado em 2014. Seu objetivo geral é "proporcionar uma formação teórica e prática baseada na conduta ética, no campo das relações humanas bem como das praticas profissionais" (UFRR, 2014, p. 10).

Quando questionamos nossos entrevistados, sobre a escolha do curso de Psicologia, pudemos observar características de formação de caráter e personalidade, quanto à preocupação com o outro:

Eu escolhi Psicologia mais para tentar auxiliar essas pessoas com deficiência porque geralmente quando a deficiência é adquirida, a pessoa acaba entrando em estado depressivo, acaba se desmotivando, acaba desistindo de sair de casa, de trabalhar, de estudar. Eu escolhi a Psicologia mais para tentar auxiliar essas pessoas. (entrevistado A$1)$.

Confrontado com essa mesma questão, nosso segundo participante, traz um fundamento para sua escolha profissional, também de grande amplitude:

Eu fui fazer Psicologia, porque a minha formação primeira é missionário, como a gente diz no evangelho, eu escutei o chamado missionário, para trabalhar com missões. Em 2012 fui à África, em Moçambique, Maputo e lá eu conheci uma ONG que trabalha com crianças, um orfanato que trabalha com crianças que foram abandonados, pais que morreram e é uma escola ao mesmo tempo aberta para a comunidade carente, e nessa ONG de 40 crianças que eram residentes 20 são aidéticas e eu fiquei com vontade de trabalhar naquele local e vi na psicologia uma possibilidade de ser útil de alguma forma para aquelas crianças ou mesmo para outros povos como... lá na África, há muitas situações, os idosos também, a vida deles é bem difícil lá. (Entrevistado A- 2 ).

Viverem com uma limitação funcional não impede esses alunos de pensarem uma formação adequada e de qualidade com vistas em se aperfeiçoar profissionalmente e contribuir com a sociedade.

\subsection{O acesso à Universidade Federal de Roraima}

Na Universidade Federal de Roraima o acesso aos cursos se dá por via do Exame Nacional do Ensino Médio - ENEM ou de vestibular que é composto de duas modalidades: Prova Integral - PI e Processo Seletivo Seriado - PSS. A Prova Integral é um processo único destinado aos candidatos que desejam realizar uma única etapa de seleção e o público-alvo são alunos que já concluíram ou estão concluindo o Ensino Médio. O processo seletivo seriado é destinado aos alunos para participação desde o primeiro ano do Ensino Médio, em que candidato deverá realizar três etapas anuais. 
A Universidade cumpre legislação federal que regulamenta as condições gerais da Lei de $n^{\circ} 12.711 /$ 2012 que trata das reservas de vagas nas Instituições Federais de Ensino e a portaria normativa n ${ }^{\circ}$ 18/2012 que fixa as condições para concorrer às vagas reservadas (BRASIL, 2012). Tais condições são: estudantes egressos de escola pública, dentro dessa reserva separam-se dois grupos, estudantes com renda familiar bruta per capita igual ou menor que 1,5 salários mínimos e estudantes autodeclarados pretos, pardos e/ou indígenas.

Oportunizar a pessoa com deficiência a ter acesso à educação em todos os seus níveis como preconiza a LDB 9394/96 “oferecida preferencialmente na rede regular de ensino” (Brasil, 1996b), ainda é um desafio, visto que o Estado tem falhado na garantia e no cumprimento da efetivação da legislação. Cury (2002, p. 261) afirma que:

O acesso à educação é também um meio de abertura que dá ao indivíduo uma chave de autoconstrução e de se reconhecer como capaz de opções. O direito à educação, nesta medida, é uma oportunidade de crescimento cidadão, um caminho de opções diferenciadas e uma chave de crescente estima de si.

Então é importante destacar que para a pessoa com deficiência a previsão legal de acesso à educação é um avanço no processo de independência e de vencer as barreiras sociais, "visto que, para além das barreiras próprias da deficiência, esses estudantes foram historicamente excluídos do direito à escola básica, o que, na maioria das vezes, impossibilitou sua chegada à universidade" (PIECZKOWSKI e NAUJORKS, 2014, p. 106-107).

No ensino superior, o sentido de direito ao acesso é restringido pela perspectiva meritocrática que embasa a própria legislação que irá definir que o acesso a ele se dará de acordo com a capacidade de cada um. Políticas de ação afirmativa tem procurado romper com essa lógica, mas ainda tem seus gargalos.

Em relação aos vestibulares, é importante observarmos tais questões pela perspectiva de quem vive essa trama. Do ponto de vista dos alunos com deficiência que participaram de nossa pesquisa, vários aspectos ainda precisam ser melhorados:

[...] vamos supor: todos os deficientes visuais, aí eles vão e tratam todos eles como se fossem um. Sendo que, cada um, tem as suas especificidades como humano. Dentro dos deficientes visuais já tem isso, quanto mais entre os deficientes. E o que eu observo quanto ao vestibular [...] Acho que deveriam facilitar ou pelo menos procurar um meio de adaptar o conteúdo à situação da deficiência que não é a mesma coisa. [...] Nisso, é olhar cada deficiência como única e olhar a especificidade de cada deficiência, não tratar todos como se fossem deficientes e pronto. (Entrevistado A-2)

O vestibular foi um pouco mais complicado, eu não gostei do atendimento. Aqui na UFRR eram vários ledores. Não era como no ENEM em que era um só ledor para todas as disciplinas que ficou comigo do começo ao final da prova. Aqui para cada disciplina era um ledor diferente e isso me confundia muito. Eu acho que isso acabou prejudicando meu desempenho na prova, porque eu ficava desatenta, ficava mudando a voz, aí eles levantavam e entrava outro ledor e isso me dificultou. Eu estava numa sala individual, 
prova com o mesmo tempo, mas porém, com vários ledores e isso me dificultava porque me desconcentrava. (Entrevistado A-1)

Cada dificuldade relatada aqui, traz a tona que, apesar dos avanços nas políticas de inclusão, na postura da comunidade acadêmica, ainda temos ajustes a fazer, pois a inclusão é um processo. A cada avanço alcançado, surgem novas demandas e, atendê-las é o nosso desafio, visto que adaptar os espaços e romper barreiras sociais é o significado do termo inclusão. Pieczkowski e Naujorks (2014, p.109) destacam que:

[...] o decreto n. 3.298/1999 determina que as Instituições de Ensino superior (IES) devam ofertar adaptações nas provas e disponibilizar os apoios necessários que forem previamente solicitados pelo candidato com deficiência. O referido Decreto aponta para o direito a tempo adicional para a realização das provas, de acordo com as características da deficiência do candidato.

Como podemos observar, o que está preconizado no plano normativo, não se efetivou no caso destes alunos, que tiveram dificuldades de acesso ao ensino superior, como destacam em seus relatos. Salientam que, embora asseguradas condições específicas para o atendimento a pessoas com deficiência, a universidade vem fazendo uma homogeneização das deficiências, não atendendo cada aluno dentro de sua especificidade, o que vem causando o apagamento da singularidade do estudante no planejamento do trabalho a ser realizado.

Apesar de nós termos um tempo a mais, por exemplo, eu sou deficiente, mas eu vou concorrer com os outros tipos de deficiência, eu vou concorrer com cadeirante, é claro que eu não estou diminuindo a dificuldade do cadeirante, mas ele tem toda a habilidade de uma pessoa, entre aspas, normal: ele enxerga, ele consegue escrever, ele não depende muito, só da mente, por exemplo, como eu, para fazer uma prova de cálculo. (Entrevistado A-2)

O que este aluno sugere, é que a universidade enxergue que as deficiências diferem uma da outra não só biologicamente, mas de pessoa para pessoa, pois o impacto que uma limitação funcional causa em uma pessoa não é o mesmo que causa em outra. E que tudo que seja feito para os alunos com deficiência seja perguntado a eles. Como nos afirma Sassaki (2007, p. 10):

Juntando as palavras [...] "Nenhum resultado a respeito das pessoas com deficiência haverá de ser gerado sem a plena participação das próprias pessoas com deficiência". Em outras palavras, as pessoas com deficiência estão dizendo: "Exigimos que tudo que se refira a nós seja produzido com a nossa participação. Por melhores que sejam as intenções das pessoas sem deficiência, dos órgãos públicos, das empresas, das instituições sociais ou da sociedade em geral, não mais aceitamos receber resultados forjados à nossa revelia, mesmo que em nosso benefício".

E é basicamente esse o objetivo deste estudo, como estudantes da área, poder contribuir para o sucesso dos alunos com deficiência no ensino superior, ouvindo suas sugestões e suas experiências de vida.

\subsection{Permanência na Universidade}


As condições de permanência na universidade são de extrema importância, pois o estado demanda custos para a estruturação dos cursos, para a manutenção de estudantes, de profissionais qualificados. A sociedade também cria expectativas em relação aos estudantes das instituições de ensino superior da rede pública e, na perspectiva da educação inclusiva, as ações que contribuem para a permanência dos estudantes, além de questões de assistência socioeconômica, também estão as questões relacionadas ao aprendizado dos estudantes com deficiência;

O aprendizado pode ser extremamente favorecido, se os estudantes tiverem acesso a recursos tecnológicos e a atendimento educacional especializado, o que nos leva a uma das contribuições importantes à permanência registrada nas entrevistas, que é o trabalho desenvolvido pelo Núcleo de Acessibilidade do qual trataremos a seguir.

\subsection{Atendimento Educacional Especializado na universidade}

O Núcleo de Acessibilidade e Inclusão da UFRR, denominado Núcleo Construir, foi criado em 2007, com o apoio do Programa Incluir (MEC), com a finalidade de implementar políticas e ações voltadas às necessidades que emergem tanto dos alunos com deficiência, quanto dos professores, acadêmicos e técnicos das universidades com a chegada de estudantes com deficiência, entre seus estudantes:

Criado em 2005, o Programa Incluir-acessibilidade na educação superior foi implementado até 2011, por meio de chamadas públicas, realizadas pela SEESP e SESU, por meio das quais, as IFES apresentaram projetos de criação e consolidação dos Núcleos de Acessibilidade, visando eliminar barreiras físicas, pedagógicas, nas comunicações e informações, nos ambientes, instalações, equipamentos e materiais didáticos (BRASIL, 2005).

Este órgão de apoio na Universidade, além de atender a pessoas com deficiência, também atende aos alunos estrangeiros, indígenas e quaisquer outros alunos que procurem o núcleo em busca de suporte pedagógico e sociocultural. "Os núcleos devem garantir o acesso de estudantes, professores e servidores com deficiência a todos os espaços, ações e processos, buscando seu pleno desenvolvimento acadêmico" (UFRR, NÚCLEO CONSTRUIR, s. d.).

Dentre as ações do Núcleo Construir de Acessibilidade da UFRR estão: o mapeamento dos alunos que apresentem demandas específicas para posterior mediação entre os alunos e seus cursos com vistas a proporcionar um ambiente favorável ao processo de ensino-aprendizagem; contato com as coordenações dos cursos para informar sobre as particularidades dos alunos atendidos; disponibilizar equipamentos e material tecnológico que subsidiem o aprendizado dos alunos; acompanhamento nas atividades curriculares e extracurriculares; capacitação dos alunos para utilizar o material tecnológico; palestras; 
aulas de nivelamento; entre outras. Além disso, realizam também o contato com os alunos com e sem deficiência que estão evadidos dos cursos no sentido de compreender melhor os processos de evasão.

O núcleo de acessibilidade desenvolve diversas ações, que contribuem para a formação dos alunos da universidade, porém nos relatos de alunos e profissionais que estão inseridos no Núcleo, ele ainda possui alguns gargalos que interferem no melhor desempenho dos alunos, que trataremos nos tópicos seguintes.

\subsection{Equipamentos tecnológicos}

O decreto n. 6949/2009 (BRASIL, 2009) reconhece que a deficiência é um conceito em evolução e que a deficiência resulta da interação entre pessoas com deficiência e as barreiras devidas às atitudes e ao ambiente que impedem a plena e efetiva participação dessas pessoas na sociedade em igualdade de oportunidades com as demais pessoas. Em seu artigo 24 preconiza:

c) Adaptações razoáveis de acordo com as necessidades individuais sejam providenciadas;

d) As pessoas com deficiência recebam o apoio necessário, no âmbito do sistema educacional geral, com vistas a facilitar sua efetiva educação;

e) Medidas de apoio individualizadas e efetivas sejam adotadas em ambientes que maximizem o desenvolvimento acadêmico e social, de acordo com a meta de inclusão plena.

O mesmo decreto n. 6949/2009, em seu artigo 4 que trata das obrigações gerais do Estado, preconiza:

g) Realizar ou promover a pesquisa e o desenvolvimento, bem como a disponibilidade e o emprego de novas tecnologias, inclusive as tecnologias da informação e comunicação, ajudas técnicas para locomoção, dispositivos e tecnologias assistivas, adequados a pessoas com deficiência, dando prioridade a tecnologias de custo acessível;

h) Propiciar informação acessível para as pessoas com deficiência a respeito de ajudas técnicas para locomoção, dispositivos e tecnologias assistivas, incluindo novas tecnologias bem como outras formas de assistência, serviços de apoio e instalações; (BRASIL, 2009)

As adaptações citadas no texto da lei também se aplicam à questão tecnológica, que tem sido uma ferramenta relevante de acesso ao conhecimento. Os estudantes que são os sujeitos desta pesquisa afirmaram em seus relatos que o avanço tecnológico foi um forte apoio para o desenvolvimento de aprendizagens e relação de conhecimento com o conteúdo, pois viabiliza o acesso às informações o que resulta em aquisição de conhecimentos.

Está sendo bom. Os professores que não tem o texto em formato digital deixam o conteúdo impresso, ou na xerox e eu levo para o Núcleo, onde eu sou bolsista e eles digitalizam o material e eu acompanho pelo computador ou pelo celular que tem um programa acessível que faz a leitura por voz. (entrevistado A-1) 
Em outros momentos, verificamos afirmações que nos permitem refletir que em alguns momentos, a instituição tem deixado a desejar no cumprimento das normas legais. O estudante A-2 sente dificuldade, pois o núcleo de acessibilidade da universidade não tem dado conta da demanda que só vem aumentando, com o ingresso de novos alunos com deficiência a serem atendidos, sem que ocorra ampliação da equipe ou de equipamentos, o que causa atrasos:

[...] a universidade me oferece os textos digitalizados. Tem um scanner, que só foi comprado quando eu entrei, porque eu conhecia esse scanner. A universidade até então não tinha esse scanner, ela só tinha material para quem era no Braille e o pessoal de baixa visão, que era lupas e aí eu falei que nem todo deficiente gosta dessas coisas. Cada pessoa é uma pessoa. Eu falei sobre esse scanner para eles e eles fizeram contato e a licitação e compraram e ele digitaliza. Como é um só e já tem mais deficientes na universidade, e quem faz as digitalizações é uma bolsista, então atrapalha muito porque atrasa. Por exemplo, eu estou com uma disciplina que até agora [dois meses após o início das aulas] eu não recebi um texto, então isso atrapalha muito. (Entrevistado A-2)

Podemos destacar que a Instituição tem dado resposta as demandas levantadas pelos estudantes mesmo que em ritmo lento. A universidade vem adquirindo novas tecnologias e materiais; qualificando pessoal; levando discussões de relevância acadêmica sobre a educação especial na perspectiva da inclusão.

Segundo o documento orientador do Programa Incluir (BRASIL, 2013) no que diz respeito à acessibilidade no ensino superior referente a currículo, comunicação e informação está previsto que “[...] garantia de pleno acesso, participação e aprendizagem das pessoas com deficiência, dá-se por meio da disponibilização de materiais didáticos e pedagógicos acessíveis; de equipamentos de tecnologia assistiva e de serviços de guia-intérprete e de tradutores e intérpretes de Libras".

O documento orientador do Programa Incluir em seus marcos legais, políticos e pedagógicos enfatiza o decreto n. 7.611/2011 que dispõe sobre o atendimento educacional especializado que, no seu parágrafo quinto prevê que os núcleos de acessibilidade nas instituições federais de educação superior visam eliminar barreiras físicas, de comunicação e de informação que restringem a participação e o desenvolvimento acadêmico e social de estudantes com deficiência.

\subsection{Acompanhamento Pedagógico}

O acompanhamento pedagógico é compreendido nesse estudo, como aquele que é feito por professores, colegas de classe mais próximos e pelo Núcleo de Acessibilidade da Universidade. Esse acompanhamento fortaleceu as relações entre pares, contribuindo para o desenvolvimento acadêmico dos alunos. Entendemos que ele se diferencia do sentido de Atendimento Educacional Especializado - AEE, conforme previsto no plano normativo e legal por ser, em muitos momentos, realizado de maneira 
tecnicamente frágil, sem considerar a efetiva especialização das pessoas que, por vezes, protagonizam o apoio aos estudantes.

Um fato em comum observado nas entrevistas, é a importância da relação com o outro, exemplificando como professores e colegas de turma podem contribuir para o desenvolvimento da aprendizagem e da socialização. Nesse sentido, o apoio de seus pares constitui um motivo primordial para a permanência e sucesso desses alunos.

Entendemos que o papel dos sujeitos não é ajudar, como um sentido caritativo, mas sim responder com responsabilidade ao que as políticas públicas estabelecem, como por exemplo, professores que devem adequar aulas, inserir metodologias de ensino que oportunizem o aprendizado dos estudantes, ouvir as necessidades dos estudantes em relação ao conteúdo e atendê-las da melhor maneira que lhes seja possibilitado.

A representação do núcleo de acessibilidade também relata sobre o acompanhamento feito pelos bolsistas aos estudantes com deficiências da universidade:

[...] assim como também tem os nossos bolsistas, tanto os bolsistas da bolsa INCLUIR que são alunos com deficiência que ajudam outros alunos com deficiência ou até outros alunos que não tem deficiência, mas que estão com uma dificuldade de aprendizagem e tem bolsistas PRÓ-ACADÊMICO e PRÓ-QUALIFICA. (Entrevistado B-1)

Por exemplo, tem um programa chamado DOSVOX que é, gratuito, os alunos que conhecem bem passaram para os outros e assim está acontecendo sucessivamente, alguns alunos aqui da universidade aprenderam com outro aluno [...](Entrevistado B-1)

Como podemos observar e problematizar na fala da atual coordenação do Núcleo, os bolsistas acabam fazendo o acompanhamento pedagógico dos alunos com dificuldades: um aluno ajuda o outro dentro de suas possibilidades, assim também acontece com o uso de equipamentos e novos softwares. Esta é uma questão que nos remete claramente à importância da mediação como preconizado por Vigotski (1999) para o desenvolvimento e aprendizado dos indivíduos, mas que precisa também ser problematizado por caracterizar-se, em muitos momentos, como ação com reduzido grau de elaboração técnica ou profissionalismo, realizando ações que seriam de responsabilidade institucional.

O trabalho de acompanhamento pedagógico que vem sendo desenvolvido pelo Núcleo de Acessibilidade, apesar de alguns gargalos ainda é o que tem sido mais citado nas falas dos entrevistados como de contribuição significativa para sua formação. Podemos analisar que de maneira simples, a atuação do núcleo através de seus profissionais e os bolsistas, vêm contribuindo para o acesso ao conhecimento/conteúdo dos estudantes com deficiência.

O acesso à informação que é disponibilizada nas aulas em tempo hábil, é o principal desafio dos estudantes. E os colegas de classe, professores e o Núcleo de Acessibilidade vem atuando para que os 


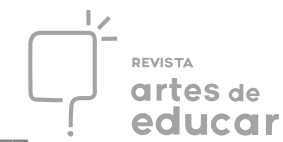

estudantes possam ter acesso. Há situações pontuais em relação a alguns colegas e professores que, ao invés de contribuir, acabam por ignorar a presença e a necessidade desses estudantes, mas essa é uma barreira atitudinal na qual este estudo, também tem a pretensão de intervir, oferecendo elementos de reflexão para a comunidade acadêmica.

\section{Considerações finais}

O objetivo de nosso estudo foi compreender a perspectiva de alunos com deficiência matriculados no curso de Psicologia da Universidade Federal de Roraima em relação ao acesso e condições de permanência e sucesso em seu percurso acadêmico. Pudemos concluir que em relação ao acesso ao Ensino superior por meio do vestibular, a opinião dos alunos destaca a necessidade de tratar com mais especificidade a condição concreta de cada indivíduo, dentro de sua deficiência, para melhor atendê-los e avaliá-los, com vistas a melhorar o acesso, desde o vestibular até a matrícula.

Em relação à permanência, os alunos relatam encontrar apoio no Núcleo Construir de Acessibilidade na UFRR, no aspecto de acesso a recursos tecnológicos e acompanhamento pedagógico e o sucesso acadêmico é vislumbrado á medida em que melhoram as condições de permanência, em especial na interlocução com os demais colegas, que desenvolveram uma postura sensível e colaborativa com os estudantes com deficiência.

Recebemos como sugestão dos alunos, continuar ouvindo o que os sujeitos centrais da pesquisa têm a dizer, o que realmente contribuiria para cumprirmos o que está posto nas políticas públicas que tem como foco a inclusão e que destacam que a sociedade tem que responder ao desafio ético de minimizar as barreiras sociais que dificultam a participação plena e efetiva de todos. Nesse sentido, o entendimento é de que o Estado brasileiro como um todo precisa se adequar administrativamente através de seu arcabouço legal, arquitetonicamente melhorando as condições de acessibilidade e tecnologicamente popularizando os recursos relativos à tecnologia assistiva e investindo nas pesquisas que podem favorecer o aperfeiçoamento dessas.

Esperamos, com esse trabalho, contribuir na reflexão da comunidade acadêmica de como remover as barreiras sociais que impedem a plena participação das pessoas com deficiência na universidade e na vida social como um todo.

Salientamos que na perspectiva dos estudantes com deficiência, todas as ações referentes à elas, devem ser decididas e articuladas com a plena participação delas, reconhecendo seu papel como sujeitos de direitos, autônomos e capazes de decidir sobre o rumo de suas próprias vidas e de protagonizar a construção dos caminhos que o levará a esta autonomia e plena participação social. 


\section{Referências:}

ALBERTI, V. Manual de História Oral. - 2. Ed. Ver. E atual. - Rio de Janeiro: Editora FGV, 2004. ALBERTI, V. Tratamento das entrevistas de história oral no CPDOC. Rio de Janeiro: CPDOC, 2005. BOSI, E. O tempo vivo da memória: ensaios de psicologia social. São Paulo: Ateliê Editorial, 2003. BRASIL. Presidência da República. Constituição da República Federativa do Brasil. Brasília: DF, 1988. Disponível em: www.planalto.gov.br. Acesso em: 02 de fev.2017.

BRASIL, Decreto $n^{o}$ 5.296, 02 de dezembro de 2004. Estabelece normas gerais e critérios básicos para a promoção da acessibilidade das pessoas portadoras de deficiência ou com mobilidade reduzida, e dá outras providências. Brasília: DF. Disponível em: http://www.planalto.gov.br. Acesso em: 02 de abr. 2017.

BRASIL, MEC.Programa Incluir, Programa de Acessibilidade na Educação Superior. Brasília: DF. 2005. Disponível em: http://portal.mec.gov.br/programa-incluir. Acesso em: 02 de abr. de 2017.

BRASIL, MEC/Secretaria de Educação Especial. Política Nacional de Educação Especial na Perspectiva da Educação Inclusiva. Brasília: MEC; Seep, 2008.

BRASIL, Presidência da República. Decreto $n^{\circ}$ 6949, de 25 de agosto de 2009. Promulga a Convenção Internacional sobre os Direitos das Pessoas com Deficiência e seu Protocolo Facultativo, assinados em Nova York em 30 de março de 2007. Brasília: DF. Disponível em: www.planalto.gov.br. Acesso em: 30 de mai. 2017.

BRASIL. Lei $n^{o}$ 12.711, de 29 de agosto de 2012. Dispõe sobre o ingresso nas universidades federais e nas instituições federais de ensino técnico e de nível médio e dá outras providências. Brasília: DF.

Disponível em: www.planalto.gov.br. Acesso em: 02 de jan. 2017.

CAJUEIRO, R. L. P. Manual para elaboração de trabalhos acadêmicos: guia prático do estudante. 2.

Ed. Petrópolis-RJ: Vozes, 2013.

CURY, C. R. J. Direito à educação: direito a igualdade, direito à diferença. In: Cadernos de pesquisa. Fundação Carlos Chagas, n. 116. São Paulo/Campinas: Autores associados, p. 245-262. 2002.

DINIZ, D.. Modelo social da deficiência: a crítica feminista. Brasília: Letras Livres. 2003. (Série Aniz, 28).

MARQUES,C. A.; MARQUES, L.P. Do universal ao múltiplo: os caminhos da inclusão. Rio de Janeiro: RJ. DP\&A, 2003.

MITTLER, P. Educação inclusiva: contextos sociais. Tradução Windyz Brazão Ferreira. Porto Alegre: Artmed, 2003. 


\section{MOREIRA, L. C. Das indagações ao cotidiano da sala de aula: perspectivas de inclusão na}

universidade. In: Baptista C.; CAIADO, K. R. e JESUS, D. M.. (Org.). Educação Especial: diálogo e pluralidade. 01. ed. Porto Alegre: Mediação, 2008, v. 01, p. 204-213.

PIECZKOWSKI, T. M. Z. NAUJORKS, M. I. - (Orgs.). Educação, inclusão e acessibilidade: diferentes contextos. Chapecó: Argos, 2014.

SASSAKI, R. K. Nada sobre nós, sem nós: Da integração à inclusão - Parte 1. Revista Nacional de Reabilitação, ano X, n. 57, jul./ago. 2007, p. 8-16.

SILVA, Luciene Maria. A deficiência como expressão da diferença. Educação em revista. Belo Horizonte. V.44, p. 111-133. 2006

SIQUEIRA, I. M.; SANTANA, C. da S. Proposta de acessibilidade para a inclusão de pessoas com deficiências no Ensino superior. Revista Brasileira de Educação Especial. V.16; p.127-136, jan-abr. 2010.

UFRR/Curso de Psicologia. Projeto Político Pedagógico do Curso de Psicologia. Disponível em: http://ufrr.br/psicologia. Acesso em: 11 de nov. 2016

UFRR/Núcleo Construir. Plataforma no site da Universidade Federal de Roraima que apresenta o Núcleo de Acessibilidade. Disponível em: http://ufrr.br/construir . Acesso em: 15 de dez. 2016

\section{Notas:}

\footnotetext{
' Mestranda no Programa de Pós-Graduação em Educação (PPGE) da Universidade Federal de Roraima (UFRR). Graduada em Pedagogia na Universidade Federal de Roraima. Pesquisadora do NEPEDE'ES - Núcleo de Estudos e Pesquisas em Direito à Educação, Educação Especial da UFRR. Docente da Prefeitura Municipal de Roraima. Email: dafnesoliveira@ gmail.com ii Doutora em Educação Especial pela Universidade Federal de São Carlos. Mestre em Educação pela Universidade Federal de Juiz de Fora. Pedagoga. Professora do Centro de Educação da Universidade Federal de Roraima. Líder do grupo de pesquisa NEPEDE’ES - Núcleo de Estudos e Pesquisas em Direito à Educação, Educação Especial da UFRR.

Email: edith.romano@ufrr.br
} 